\title{
Effect of minor changes in dietary habits by consumption of small amounts of raw vegetables and fruits on BMI, Blood Glucose and lipid profile
}

\author{
Rohini Bhadri', Shobha Kini ${ }^{2, *}$ \\ Professor, ${ }^{1}$ Dept. of Biochemistry, ${ }^{2}$ Dept. of Physiology, K. J. Somaiya Medical College and Research Centre, Mumbai \\ *Corresponding Author: \\ Email: shobhakini@ somaiya.edu
}

Received: $16^{\text {th }}$ October, 2017

Accepted: $07^{\text {th }}$ December, 2017

\begin{abstract}
A good dietary regime is important for health. But to follow a particular regime is hurricane task. It is known from previous studies that there is an association between vegetarian diet and low total serum cholesterol as well as LDL-cholesterol. Fruits and vegetables being rich sources of fiber and antioxidants have been the focus in our interventional study. Our current study focused on the difficulty of a change in the dietary habits, hence with a minor change in the daily diet for 90 days, we assessed the effect on the BMI, lipid profile and blood sugar

Materials and Methods: 30 Teaching and Non teaching faculty of our college were included in the study. The age group was between 25 and $60 \mathrm{yrs}$ of age with no metabolic disorders. Their BMI was calculated, Biochemical parameters were measured which included Lipid profile and Blood sugar before and after intervention. A slight modification in the diet was suggested with addition of raw vegetables and sprouts for a period of 90 days.

Result: BMI was decreased from $26.8 \mathrm{~kg} / \mathrm{mt} 2$ to $25.8 \mathrm{~kg} / \mathrm{mt} 2$.Mean Lipid profile values in $\mathrm{mg} / \mathrm{dl}$ for Total cholesterol pre and post were $205 \pm 36.83$ and 196.4 \pm 32.95 , HDL cholesterol pre and post were $46.0 \pm 6.9$ and $44.8 \pm 7.38$, LDL cholesterol pre and post were $130.1 \pm 28.51$ and $126.0 \pm 27.33$, TG pre and post were $144.3 \pm 89.75$ and $126.32 \pm 48.93$ and the CRI was $4.5 \pm 0.8$ and $4.4 \pm 0$.6. Blood glucose pre and post 94.33 to $89.2 \mathrm{mg} / \mathrm{dl}$. Most of the results were statistically not significant.

Conclusion: Even a minor change in the diet can definitely have a good effect in lowering the BMI, lipid profile and Blood sugar.
\end{abstract}

Keywords: Fruits, vegetables, Cholesterol, BMI, Triglycerides.

\section{Introduction}

In today's era there is a trend towards ready to eat processed food which may be unhealthy. A good dietary regime is important for health. But to follow a particular regime is hurricane task. It is known from the previous studies that there is an association between vegetarian diet and low total serum cholesterol, LDLcholesterol and Blood sugar. ${ }^{1,2}$ The World Health Organization estimates that low fruit and vegetable intake is responsible for 31 percent of ischemic heart diseases and 11 percent of strokes. ${ }^{3}$ Fruits and vegetables are rich in a wide variety of micronutrients and other dietary components, such as fiber and phytoestrogens, further suggesting that the joint effects of multiple nutrients may be more important than the actions of single nutrients. Folate, is a micronutrient which is found largely in fruits and vegetables and also vitamin $\mathrm{C}$ which is found in high contents and has an antioxidant effect. ${ }^{3}$

The recommended intake of raw vegetables and fruits is at least five portions about $500 \mathrm{gms}$ per day to reduce cholesterol and triglyceride levels. ${ }^{4}$ It is difficult to consume such high amounts for a large section of our population.

Hence our study is focused on the difficulty of a change in the dietary habits, and therefore instead of five portions we introduced four portions in their diet only 6 days a week for 3 months and assessed the effect on the BMI, lipid profile and blood sugar.

\section{Materials and Methods}

The study designed is non randomized experimental Nutritional Interventional study. Ethical Clearance was taken from the ethical committee of our Institute. The study included 35 Teaching and Nonteaching faculty members of our college. However 5 subjects dropped out as they were not able to adhere to the diet. The age group was between 25 and 60 years of age. Exclusion criteria was any metabolic disorders. Their Physiological and Biochemical parameters were measured before and after the intervention. Physiological parameters included height, weight and BMI. Height was measured using a stadiometer and weight was measured on a standard weighing scale with light clothes and without shoes. Biochemical parameters included Lipid profile and Blood sugar .The subjects after undergoing this test were given a questionnaire. The questionnaire included questions relating to their daily activities and their food habits. Taking this questionnaire into consideration a diet was given to all subjects, from their original diet depending upon the type of food they consumed about $25 \mathrm{gms}$ of cooked rice or chappatti weighing $25 \mathrm{gms}$ was reduced from the diet and the subjects were asked to consume $100 \mathrm{gms}$ of any seasonal fruit for breakfast. $50 \mathrm{gms}$ of 
raw vegetable salad for lunch and dinner. The salad could include tomatoes, cucumber, carrots, cabbage, green, red or yellow pepper. In the evening they were asked to consume $50 \mathrm{gms}$ of sprouts. The total amount of raw food consumed per day was $250 \mathrm{gms}$. The follow up of the subjects for their dietary regime was monitored every week. After three months the same Physiological and Biochemical parameters were measured.

Blood Glucose was estimated by GOD- POD method on Pictus 400 using Accurex reagent Serum Total Cholesterol -using Siemen's Kit, Serum Triglycerides by enzymatic method using Siemen's Kit and HDL- Direct method, Cholesterol by CHOD-POD using Spinreact Kit. LDL -cholesterol and VLDLcholesterol by calculation.

\section{Statistical Analysis}

Statistical analysis was carried out using the Primer software, data was analyzed using the paired $\mathrm{T}$ test and Wilcoxon Test.

\section{Result}

The results are as follows:

\begin{tabular}{|c|c|c|c|c|}
\hline \multirow{3}{*}{ FBS } & & Mean & $\begin{array}{l}\text { Standard } \\
\text { deviation }\end{array}$ & p value \\
\hline & Pre & 94.33 & \pm 18.32 & \multirow{2}{*}{0.03} \\
\hline & Post & 89.27 & \pm 13.43 & \\
\hline \multirow{2}{*}{$\begin{array}{l}\text { Total } \\
\text { Chol }\end{array}$} & Pre & 205.03 & \pm 36.83 & \multirow{2}{*}{0.005} \\
\hline & Post & 196.35 & \pm 32.95 & \\
\hline \multirow{2}{*}{$\begin{array}{l}\text { HDL } \\
\text { Chol }\end{array}$} & Pre & 46.033 & \pm 6.90 & \multirow{2}{*}{0.025} \\
\hline & Post & 44.780 & \pm 7.38 & \\
\hline \multirow{2}{*}{$\begin{array}{l}\text { LDL } \\
\text { Chol }\end{array}$} & Pre & 130.103 & \pm 28.51 & \multirow{2}{*}{0.184} \\
\hline & Post & 126.057 & \pm 27.33 & \\
\hline \multirow[t]{2}{*}{$\mathrm{TG}$} & Pre & 144.27 & \pm 89.75 & \multirow{2}{*}{0.112} \\
\hline & Post & 126.32 & \pm 48.93 & \\
\hline \multirow{2}{*}{$\begin{array}{l}\text { HDL/ } \\
\text { Total } \\
\text { Chol }\end{array}$} & Pre & 4.54 & \pm 1.03 & \multirow[b]{2}{*}{.469} \\
\hline & Post & 4.47 & \pm 0.90 & \\
\hline \multirow[t]{2}{*}{ BMI } & Pre & 26.8 & \pm 3.22 & \multirow{2}{*}{0.0001} \\
\hline & Post & 25.8 & \pm 3.17 & \\
\hline
\end{tabular}

$\mathrm{p}$ value less than 0.05 is significant.

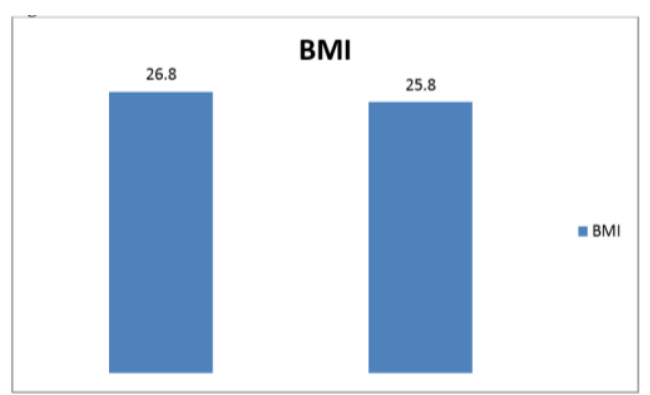

$\mathrm{p}$ is significant

Fig. 1: Correlation of BMI Pre and Post Intervention

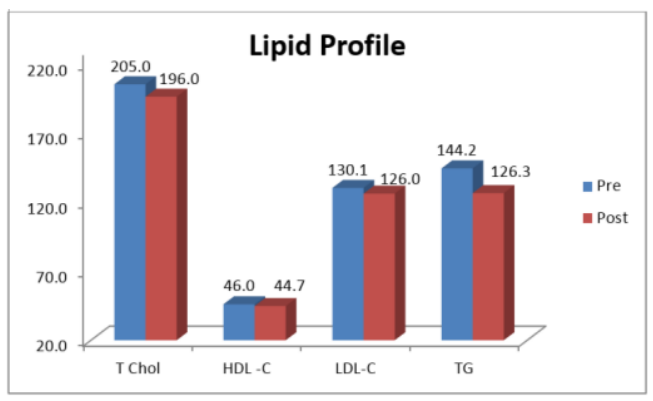

Fig. 2: Correlation of Lipid Profile Pre and Post Intervention

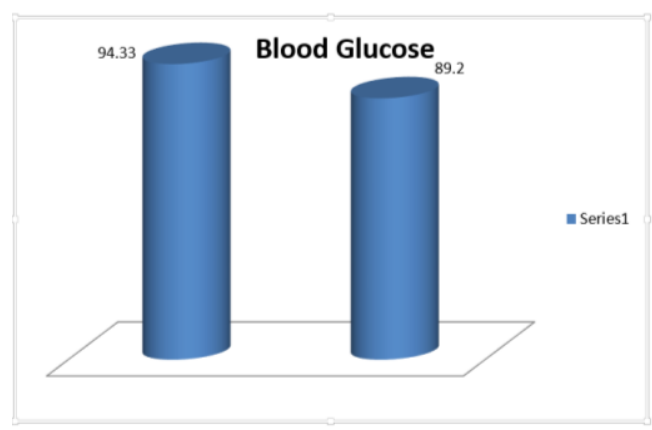

$\mathrm{p}$ is not significant

Fig. 3: Correlation of Blood Glucose Pre and Post Intervention

\section{Discussion}

Diets high in fruits and vegetables are widely recommended for their health-promoting properties. Fruits and vegetables have historically held a place in dietary guidance because of their concentrations of vitamins, especially vitamins $\mathrm{C}$ and $\mathrm{A}$. These are also a rich source of minerals and phytochemicals which have antioxidant effect. Additionally, fruits and vegetables are recommended as a source of dietary fiber. ${ }^{5}$

The World Health Organization (WHO) recommends that a minimum of 5 servings of fruits and vegetables should be consumed daily in order to obtain health benefits. ${ }^{6}$

Fruits and Vegetables are also known to reduce weight, as seen in the study carried out by Sartorelli D $\mathrm{S}$ et al and a study by de Oliveria MC.,8 Our study could be compared with these studies where we found that the BMI was reduced from $26.8 \mathrm{~kg} / \mathrm{mt}^{2}$ to $25.8 \mathrm{~kg} / \mathrm{mt}^{2}$.

In a study carried out in Thailand by Sapwarobol Suwimol which was published in Food and Public Health 2012 where the subjects were divided into three groups consuming 3,5 and 8 servings of fruits and vegetables per day for a period of 4 weeks all days, the lipid profile was not found to be significantly different except for LDL cholesterol in those who had consumed 5 and 8 servings per day. ${ }^{9}$

The study which we carried out in our Institute, we changed the dietary habits of the subjects by introducing four servings of fruits and vegetables per 
day for six days of a week. This dietary regime was followed for 12 weeks. We found the concentration of triglyceride was $144.3 \mathrm{mg} / \mathrm{dl}$ at the base and decreased to $126.3 \mathrm{mg} / \mathrm{dl}$ after 12 weeks. The level of Total Cholesterol was decreased from $205 \mathrm{mg} \%$ to 196.4 $\mathrm{mg} \%$ which was significant. The $\mathrm{LDL}-\mathrm{C}$ was reduced from $130.1 \mathrm{mg} / \mathrm{dl}$ to $126.1 \mathrm{mg} / \mathrm{dl}$. There was also a decrease in HDL-C and the HDL $-\mathrm{C}$ to Cholesterol ratio (CR Index) was decreased. Our study could be compared with similar types of studies.

The decrease in Total Cholesterol, LDL -C, VLDL$\mathrm{C}$, Triglycerides and CR Index could be attributed to the antioxidant effect. Antioxidants are able to scavenge free radicals. Among them vitamins like folic acid, and ascorbic acid are potent antioxidants that are known to prevent LDL from oxidation. Vitamin $\mathrm{C}$ is the most potent antioxidant and prevents LDL peroxidation and improves endothelial function. ${ }^{10}$

Dietary fiber content is positively correlated with the intake of whole grains, fruits, and vegetables. ${ }^{11,12}$ Fibers increase satiety and reduce appetite, ${ }^{13,14}$ another important benefit is their action on the gastrointestinal tract, is that they reduce gastrointestinal transit time thus helping to eliminate cholesterol, thus reducing serum total cholesterol levels. ${ }^{15,16}$

In a study, in African population, where local fruits and vegetables have been shown to be rich in dietary fiber have been reported to have hypocholestrolemic effects. ${ }^{17,18}$ The plant sterols which are found in them produce a reduction of plasma low-density lipoproteincholesterol. ${ }^{1,19}$

In a similar study by Olugbenga Adebawo et al where the subjects were asked to consume edible portion of fruits and vegetables of $300 \mathrm{gms}$ for a period of 8 weeks for all days and the lipid profile parameter was measured at 8th week, a significant difference was seen between the baseline value for all the lipid profile parameters except HDL. ${ }^{1}$

In our study HDL-C was found to be decreased whereas in a study carried out by Khorgade where he has divided the subjects into three groups according to their income it was found that HDL $-\mathrm{C}$ was increased from $42 \mathrm{mg} / \mathrm{dl}$ to $43 \mathrm{mg} / \mathrm{dl}$ in High income group but was not significant, middle income group it remained same and in lower income group HDL-C decreased from $49 \mathrm{mg} / \mathrm{dl}$ to $48 \mathrm{mg} / \mathrm{dl}$ but was not significant. ${ }^{20}$ This could suggest that the joint effect of multiple antioxidant and fibers is not sufficient for HDL - C levels to be increased. In our study the subjects did not change their physical activity, and there are studies which correlate HDL-C levels with physical activity. In a few studies it is shown that endurance exercise training can increase plasma HDL cholesterol levels, if the exercise training stimulus is sufficient. ${ }^{21,22}$

Obesity and physical inactivity are most important risk factors for type 2 diabetes, but recent evidence suggests that oxidative stress play an important role in pathogenesis of this disease. ${ }^{23}$ Increased insulin resistance and higher glucose and free fatty acids levels can increase the amount of active oxygen and generate oxidative stress in the body, ${ }^{24-26}$ even free radicals impair insulin action through changes in the physical condition of target cell membrane..$^{27-29}$

Antioxidants not only improve insulin secretion and performance by neutralizing free radicals, and also improve regulation of blood sugar. ${ }^{30}$ Fruits and vegetables are considered as rich resources in certain antioxidants, including carotenoids, vitamins A, C, E and some minerals such as selenium and Zinc.

In our study we found the fasting Blood sugar levels decreased from base line of $94.3 \mathrm{mg} / \mathrm{dl}$ to 89.2 $\mathrm{mg} / \mathrm{dl}$ after three months of intervention.

Marjan Tabesh et al in their study on the correlation between intake of fruits and vegetables in relation with glycosylated $\mathrm{Hb}$, found that the $\mathrm{HbA} 1 \mathrm{c}$ was $9.3 \%$ in patients without fruits and vegetables .If fruit consumption is assumed constant, increasing consumption of 10 grams vegetables caused reduction 0.03 percent of glycosylated (HbA1C) and this effect is borderline significant $(P=0.049)$, and if vegetables consumption was assumed to be constant, increasing consumption of 10 grams of fruits, decreased 0.02 percent of glycosylated hemoglobin but this effect was not significant.

When the effect of both of fruits and vegetables consumption on glycosylated hemoglobin (HbA1C) was considered, they found that by increasing consumption of 10 grams of fruit and vegetables, glycosylated hemoglobin (HbA1C) significantly decreased by 0.02 percent $(P=0.014) .{ }^{31}$

According to another study by Lupo, in parts of the world where Mediterranean diet, including fruits and vegetables and oilseeds is high, the prevalence of type II diabetes are less. ${ }^{32}$

\section{Conclusion}

Consumption of small amounts of raw vegetables and fruits which is easy to follow on a long term basis is beneficial to keep the lipid profile, Blood sugar and $\mathrm{BMI}$ in its normal levels.

\section{References}

1. Olugbenga Adebawo, Bamidele Salau, Esther Ezima, Olamilekan Oyefuga,Emmanuel Ajani, Gbolahan Idowu, Adekunle Famodu and Odutola Osilesi “Fruits and vegetables moderate lipid cardiovascular risk factor in hypertensive patients" Lipids in Health and Disease 2006, 5:14

2. Mohammad Asif, "The role of fruits, vegetables, and spices in diabetes" International Journal of Nutrition, Pharmacology and Neurological Diseases Review Article,Year : $2011 \mathrm{Vol}:$ 1, Issue:1.Page:27-35.

3. WHO (World Health Organization). 2002. The world health report 2002. Geneva.

4. Cardiovascular Review Group, Committee on Medical Aspects of Food Policy (COMA). Nutritional aspects of 
cardiovascular disease (46): Department of Health report on health and social subjects. London: HMSO,1994.

5. Joanne L. Slavin' and Beate Lloyd "Health Benefits of Fruits and Vegetables" Adv Nutr July 2012 Adv Nutrvol. 3: 506-516, 2012

6. FAO/WHO. Diet, Nutrition and the Prevention of Chronic Diseases. Report of A joint FAO/WHO Expert Consultation. Geneva: World Health Organization, 2003

7. Sartorelli DS, Franco LJ and Cardosa MA " High intake of fruits and vegetables predicts weight loss in Brazillian overweight adults. Nutr. Res. 2008 Apr;28(4):233-8.

8. de Oliveira MC, Sichieri R, Venturim Mozzer R “A lowenergy-dense diet adding fruit reduces weight and energy intake in women " Appetite 2008 Sep; 51 (2):291-5.

9. Sapwarobol Suwimol, Luangcharoenkul Pimpanit, Metavee Aporn, Singlaw Pichita, Seawsiri Ratiyaporn, Jiamjarasrangsi Wiroj, Impact of Fruit and Vegetables on Oxidative Status and Lipid Profiles in Healthy Individuals Food and Public Health 2012, 2(4):113-8.

10. Farzaneh Montazerifar, Mohammad Hashemi, Mansour Karajibani, Madhurima Dikshit, .Effect of antioxidant vitamins on lipid profile and total antioxidant capacity in hemodialysis patients, ScopeMed ,2010;35(2)

11. Larsson SC, Mannisto S, Virtanen MJ, Kontto J, Albanes D, Virtamo J. Dietary fiber and fiber-rich food intake in relation to risk of stroke in male smokers. Eur J Clin Nutr. 2009; 63(8):1016-24.

12. Hamulka J, Wawrzyniak A, Sosinska S. Evaluation of dietary fibre, soluble and insoluble fibre food intake in Polish households in years 1996-2005. Rocz Panstw Zak1 Hig. 2008; 59(2):211-21.

13. Hosseinpour-Niazi S, Mirmiran P, Sohrab G, HosseiniEsfahani F, Azizi F. Inverse association between fruit, legume, and cereal fiber and the risk of metabolic syndrome: Tehran Lipid and Glucose Study. Diabetes Res Clin Pract. 2011;94(2):276-83.

14. Burton-Freeman B. Dietary fibre and energy regulation. J Nutr 2000;130:272S-5S.

15. Rosado JL, del RAM, Montemayor K, Garcia OP, Caamano MC. "An increase of cereal intake as an approach to weight reduction in children is effective only when accompanied by nutrition education: A randomized controlled trial”. Nutr J. 2008;7:28.

16. Rita De Cássia Ribeiro-Silva, Luce Alves Da Silva and Maria Cristina Teixeira Cangussu, "Effect of actions promoting healthy eating on students' lipid profile: A controlled trial "Rev.

Nutr. vol.27 no.2 Campinas Mar./Apr.2014

17. Osilesi O: "Influence of Dietary Energy source on hypertensives Nig." Nutr. Sci 1998., 9(i)

18. Osilesi O, Trout DL, Ogunwole JO, Glover E: "Blood pressure and plasma lipid during ascorbic acid. Supplementation on boarder line". Hypertensive and normotensive adults Nutr Rs 1991, 11:405-12.

19. Kozlowska-Wojcichnowska M, Jastrzebska M, Naruszewie $M$ and A Foltynska Impact of margarine enriched with plant sterols on blood lipids, platelet function land fibrinogen level in young men. Metabolism 2003: 52 (11): 1373 -8. 24.

20. Khogare, D.T. "Effect of dietary fiber on blood lipid profile of selected respondent" International Food Research Journal 19(1):297-302 (2012).

21. Richard N. Fogoros, MD," Exercise and HDL Cholesterol- Rise in HDL Correlates Best With Duration of Exercise Sessions" Updated June 23, 2016, https://www.verywell.com/exercise-and-hdl-cholesterol1745833
22. Charles Couillard, Jean-Pierre Després, Benoît Lamarche, Jean Bergeron, Jacques Gagnon, Arthur S. Leon, D.C. Rao, James S. Skinner, Jack H. Wilmore, Claude Bouchard, "Effects of Endurance Exercise Training on Plasma HDL Cholesterol Levels Depend on Levels of Triglycerides Evidence From Men of the Health, Risk Factors, Exercise Training and Genetics (HERITAGE) Family Study “, Arterioscler Thromb Vasc Biol. 2001;21:1226-32.

23. Oberley LW. "Free radicals and diabetes." Free Radic Biol Med. 1988;5:113-24.

24. Rosen P, Nawroth PP, King G, Moller W, Tritschler HJ, Packer $\mathrm{L}$. The role of oxidative stress in the onset and progression of diabetes and its complications: A summary of a Congress Series sponsored by UNESCOMCBN, the American Diabetes Association and the German Diabetes Society. Diabetes Metab Res Rev. 2001;17:189-212.

25. Nishikawa T, Edelstein D, Brownlee M. The missing link: A single unifying mechanism for diabetic complications. Kidney Int Suppl. 2000;77:26-30.

26. West IC. Radicals and oxidative stress in diabetes. Diabet Med. 2000;17:171-80.

27. Paolisso G, Giugliano D. Oxidative stress and insulin action: Is there a relationship? Diabetologia.1996;39:35763.

28. Rudich A, Kozlovsky N, Potashnik R, Bashan N. Oxidant stress Reduces insulin responsiveness in 3T3-L1 adipocytes. Am Physiol. 1997;272:935-40.

29. Brownlee M. Biochemistry and molecular cell biology of diabetic complications. Nature. 2001;414:813-20.

30. Ylonen K, Alfthan G, Groop L, Saloranta C, Aro A, Virtanen SM, et al. Dietary intakes and plasma concentrations of carotenoids and tocopherols in relation to glucose metabolism in subjects at high risk of type 2 diabetes: The Botnia Dietary Study. Am J Clin Nutr. 2003;77:1434-41.

31. Marjan Tabesh, Mitra Hariri, ${ }^{1,2}$ Gholamreza Askari, ${ }^{1,2}$ Reza Ghiasvand, ${ }^{1,2}$ Maryam Tabesh, ${ }^{1,2}$ Asieh Heydari, ${ }^{1,2}$ Leila Darvishi, ${ }^{1,2}$ and Fariba Khorvash ${ }^{1,2}$ The Relationship Between Vegetables and Fruits Intake and Glycosylated Hemoglobin Values, Lipids Profiles and Nitrogen Status in Type II Inactive Diabetic Patients

32. Lupo A. Nutrition in general practice in Italy. Am J Clin Nutr. 1997;65:1963S-6. 